\title{
Philip Grey
}

Lektor at Bjørkelangen videregående skole

\section{Jana Echevarría, MaryEllen Vogt og Deborah J, Short: Making Content Comprehensible for English Learners, The SIOP Model}

\section{Book review}

Jana Echevarría, MaryEllen Vogt og Deborah J, Short: Making Content Comprehensible for English Learners, The SIOP Model, Fourth Edition

Upper Saddle River: Pearson, 2013.

340 pages

ISBN: 978-0-13-306076-8

Let me begin by explaining why I am writing this book review in English. It is not because my intended audience is English teachers. On the contrary, I believe that in Norway Making Content Comprehensible for English Learners: The SIOP Model will be most relevant for teachers of almost

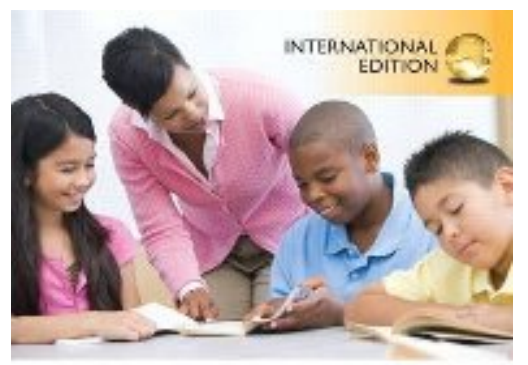

Making Content Comprehensible for English Learners

The SIOP' Model

reun-astion.

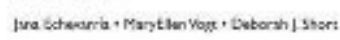
every other subject than English. I am writing this book review in English because I am not competent in academic Norwegian, that is "the set of words, grammar, and organizational strategies used to describe complex ideas, higherorder thinking processes, and abstract concepts”, to quote Zwiers (2008). I have acquired social Norwegian during my time in this country, through everyday interaction with Norwegians and Norwegian media. In the context of the United States, Echevarría, Vogt and Short argue that

for English learners to become fluent in academic English, they need to be provided with structured opportunities in all subject areas to practice using the language ... all teachers are teachers of English, even if their content specialization is science, math, or social studies. The integration of language development across the curriculum is vital. (144)

Anyone familiar with the expression norsk $i$ alle fag will recognize this argument, and it stands at the centre of the Sheltered Instruction Observation Protocol (SIOP) model. Aimed at teachers who have students who are learning in and through a new language, the main goal is to prepare non-native speakers for life after school by helping them to become competent in academic language. To achieve this goal, the authors have developed a model which offers teachers an effective way to plan and implement lessons. This book being the fourth edition, the model has already been employed at all levels of the education system in the United States, and has therefore undergone a process of 
refinement based on academic research. The model comprises eight components, which in turn consist of a total of thirty specific features. Before evaluating the model I will briefly describe the eight components.

The most striking feature of the SIOP model is that both content concepts and academic language are systematically and consistently taught simultaneously. Practising what they preach, the authors begin each chapter of the main body of the book by explicitly listing the content and language objectives in focus, as they argue teachers should do at the beginning of each lesson. Far from being a simple reminder to teachers that it is a good idea to make students aware of the lesson's specific goals, Chapter 2 explains precisely how teachers can formulate clearly defined content and language objectives. Here the reader will find a wealth of useful advice on lesson preparation, with a checklist for evaluating one's goals, meaningful activities that integrate lesson concepts with language practice and, as in all the subsequent chapters, ideas for differentiating lessons. Also included in every chapter are teaching scenarios where three specific lessons are described, evaluated and discussed.

The other seven components of the SIOP model are Building Background, Comprehensive Input, Strategies, Interaction, Practice and Application, Lesson Delivery and Review \& Assessment. Each lesson begins with the teacher introducing the content and language objectives, building background or activating prior knowledge and introducing key vocabulary. A learning strategy will have been selected and higher-order questions created for students to focus on. The teacher must also develop a scaffolding approach for teaching the new information, plan for student interaction, give the students a chance to practise with the new material and, finally, assess their understanding of concepts and language. The components are explained in a very clear way, with many concrete examples, including sample lesson plans. The book concludes with three chapters on issues of reading, lesson observation and assessment and frequently asked questions.

As I see it, there are two ways of using Making Content Comprehensible for English Learners: The SIOP Model. The first would be to adopt the model in its entirety and to use it across the curriculum to teach content and language simultaneously to non-native speakers. This would involve decision-making at the administrative level and an investment in teacher training. The authors suggest that it might take a year to become an effective SIOP teacher and a further one or two years before teachers master all thirty features of the model. One of the benefits of school-wide use of the model is that it provides a common language and conceptual framework from which to develop a common set of practices. However, given that all the material is in English, such a broad, longterm project would ideally involve the translation of key vocabulary and documents into Norwegian, such as the protocol for peer observation and feedback. The second way to use the book would be as a resource bank for planning and implementing lessons. Here teachers will find old favourites such 
as jigsaw text reading and more recent activities like word clouds. The tasks designed to promote higher-order thinking skills are particularly valuable, as are the suggestions for teaching academic vocabulary. It could thus been seen as a complement to Selj and Ryen’s (2008) Med språklige minoriteter i klassen.

While the emphasis on student engagement, social interaction and contextualized communication clearly draws on Vygotsky, and the terminology and theoretical background of the Comprehensible Input component is borrowed from Kraschen, the SIOP model is ultimately a framework which allows teachers the freedom to choose from a wide variety of techniques based on different theories. The ideas are well documented and the academic references are expansive and up to date. Frequently referred to as "research-validated", the main selling point for the model is that it has been field tested in two large research studies in which students who were exposed to a high degree of SIOP features performed better than students who were not.

The main critical question which can be raised concerns the relevance and applicability of the model in Norway. The United States, with its large Hispanic population and ever increasing number of immigrants, can perhaps more easily justify embarking on an approach which teaches content and language simultaneously. It is an approach which requires long-term investment and a commitment from teachers of all subjects across the curriculum. Although content teachers are not expected to become grammar experts, they are required to formulate language objectives for every lesson, and plan lessons designed to meet those objectives, as well as meeting the objectives of their particular subject area. Obviously the model would be most relevant to schools and districts in Norway with a high percentage of minority language speakers.

Having begun by saying that within the content of the Norwegian education system English teachers are not the main target group for the SIOP model, it is worth remembering that many Norwegian students also have to acquire skills in academic English in order to be successful in further and higher education, at home as well as abroad. Consequently, the SIOP model could be adopted in English classes, particularly on the elective courses in the final two years of videregående.

Finally, I would like to return to the penultimate chapter, in which the SIOP protocol is presented. This protocol is a tool for assessing the quality of teaching, and can be used in a variety of situations. The authors list the following: for administrators who wish to observe teachers and provide clear and concrete feedback; for teachers to help them reflect over their own lessons and improve their own practices; for peer coaching; as a university training resource; as a research instrument. Appendix A is a 9-page assessment document which allows observers to grade all thirty features of the SIOP model on a scale from zero to four. Each feature is assigned equal weight, so if all thirty features are applicable for a particular lesson the highest possible score is 120. At the very least Appendix A provides a detailed example of an assessment 
protocol which could be used as a starting-point and adapted to fit particular lesson observations. However, as mentioned earlier, the material should ideally be translated into Norwegian.

\section{References}

Selj, E., and E. Ryen (eds.) (2008). Med språklige minoriteter i klassen: Andrespråkslcring og andrespråksundervisning. Oslo: Cappelen akademisk forlag.

Zwiers, J. (2208). Building academic language: Essential practices for content classrooms. San Francisco, CA: John Wiley \& Sons, Inc. 